\title{
Significance of Mechanical Design Laboratory on Student Projects, A Preliminary Study
}

\author{
Raymond K. Yee \\ San Jose State University
}

Introduction

Engineering courses emphasize analysis and problem solving abilities a great deal. Many of the homework assignments are designed for developing these analytical skills. However, besides analytical skills, creative thinking, communication, and teamwork skills are also very important from the university's perspective. Design projects for engineering classes can complement the development of these skills in students' learning. Therefore, an environment that can foster such skill development can be an important part of the undergraduate engineering education. For this reason, a mechanical design lab was developed last year in the Mechanical and Aerospace Engineering Department (MAE) at San Jose State University (SJSU).

Senior Design Project integrates both analytical and teamwork skills into the engineering curriculum at SJSU. The newly developed Mechanical Design Lab (referred to as the "Lab") consists of computer systems that provide CAD and solids modeling, finite element analysis, design optimization, and rapid prototyping capabilities as well as access to the Internet for information. How this Mechanical Design Lab environment facilitates students to perform their senior design projects is currently being studied, and the preliminary assessment is presented in this paper.

\section{Senior Project}

As part of the engineering curriculum in the Department of Mechanical and Aerospace Engineering at San Jose State University, all students majoring in mechanical engineering are required to enroll in the Senior Design Project course in their senior year. The goals of this course are to provide students with the opportunity to experience project management such as planning, budgeting, part procurement and scheduling, to appreciate teamwork and collaboration, and to learn the design process from concept generation to prototype fabrication and validation of the final design. The proposed design project must be practical in nature, yet challenging, and must be approved by a faculty advisor. Students work in a team of 3 to 4 throughout the academic year to find solutions that meet project design goal. The senior project starts in the Fall semester and the team is required to complete their project by the end of Spring semester.

The primary objective of the senior design project is to provide students with the opportunity to draw upon previous course work and to apply what they have learned to the design project. The secondary objective of the project is to simulate industrial reality by promoting teamwork through which communication and cooperative learning skills can be developed. The third objective of the project is to learn how to give an effective oral briefing in front of peers and local industrial representatives. The remaining of this paper will discuss the preliminary 
assessment and the experience learned from two senior project groups utilizing the Mechanical Design Laboratory for developing their projects in the Fall semester.

Researchers have studied the effects of physical environment on team performance and found that teams working together outperform individuals acting alone, especially when performance requires various skills, decision-making, and experience ${ }^{1}$. Team performance is a function of team knowledge and skills, team cohesiveness, and resources available to them ${ }^{2}$. If resource availability is a major factor in team performance, then even with a high level of team skill and knowledge, a lack of available resources will hinder team effectiveness ${ }^{3}$. Based on these findings, it is important to have a designated place equipped with necessary tools where team members can meet and conduct their design project without moving from place to place.

\section{Mechanical Design Approach}

Since one of the objectives of the senior project is to simulate industrial reality in design, the design process ${ }^{4}$ commonly used in industry was introduced in the class. Basically, most of the product design projects are initiated by identifying the needs for the market. The product development can be either market-driven or new technology-driven. Once the needs are identified, the first thing to do is plan for the design. This may include forming the design team, developing the required tasks, and establishing a project schedule. Employing concurrent engineering, design team usually consists of project manager, design project engineer, manufacturing engineer, material engineer, and quality assurance engineer. Depending on the size of a company, a person may serve in multiple roles as mentioned earlier.

Secondly, engineering specifications are developed based on who the customers are, what their requirements are, and what the competing products are, etc. Based on the answers to these questions, a set of design targets is generated. These targets basically become engineering specifications with quantitative values. Thirdly, using these engineering specific ations as the targets for design, design concepts are developed based on the functions to be provided by the design. At this stage, brainstorming, creativity, and ideas from existing products and patent offices are employed. Usually several engineering concepts are generated for just one design and the most promising concept is selected from the outcome of careful comparison of the concepts. Fourthly, once the concept is finalized, the product design will be developed. In this final stage of the design, its performance will be evaluated, a cost estimate will be developed, and design for assembly and manufacturability will all be taken into consideration. Design reviews will be performed at each stage of the design process and feedback will be used as in puts for the next iterative process in design until the design of a product is satisfied.

The design process described above was introduced in the capstone design course during lecture. In this senior project class the material was reviewed again by reading assignment so that the students can use it as a guide in their senior design projects.

Significance of Design Laboratory Environment on Projects

The Mechanical Design Lab developed in 2001 consists of two bench top computer systems that provide CAD (computer-aided design) and solids modeling, kinematics design analysis, finite element analysis, and design optimization capabilities. The computers are able to access the

Proceedings of the 2002 American Society for Engineering Education Annual Conference \& Exposition Copyright () 2002, American Society for Engineering Education 
Internet so that students can search for information on the Web. Basic mechanical component catalogs such as those for gears, springs, bearings etc. are available on the shelves in the Lab. Rapid prototyping capability for model making was added to the Lab in the late Fall 2001. In addition, the Lab is also equipped with whiteboards and markers, benches, tables, and chairs, overhead projector and screen for group discussion and interaction. Figure 1 shows a project team working on their project in the Lab.

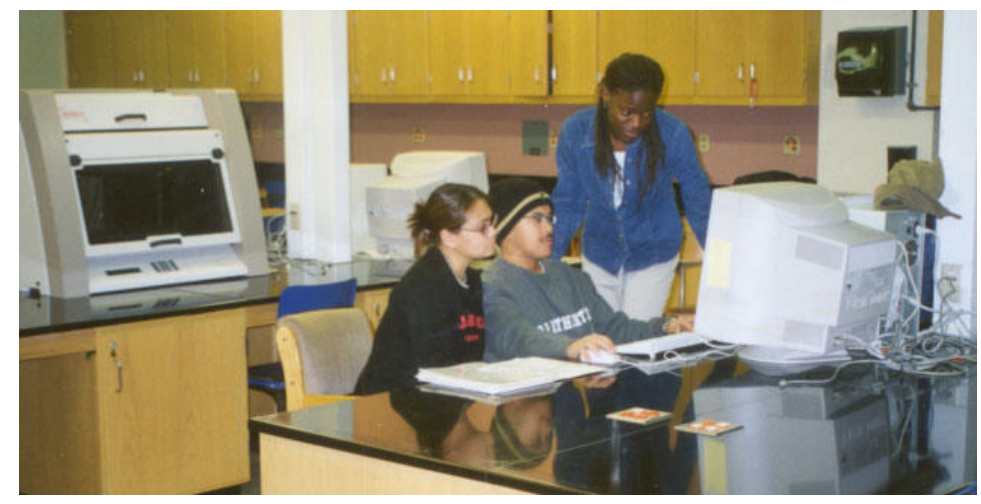

Figure1 Mechanical Design Lab

A bench top computer is shown on the table and members of a project team were looking at the analysis results in the computer.

A Stratasys rapid prototyping machine is shown on the left table in this figure.

As a pilot program to study the effects of the Mechanical Design Lab on student project quality, two senior project groups were given full access to the Mechanical Design Lab facilities. There were only two groups because only two computer systems had been set up in the Lab at that time. The first group's project was to optimize the frame design of a chariot bike (shown in Figure 2) and to add motor capability to it. The second group's project was to design a Formula style racecar for the weekend autocross racer. The car needed to be high performance, robust, adjustable, and easy to maintain. The car frame design is shown in Figure 3. The racing car will also have a custom design suspension system.

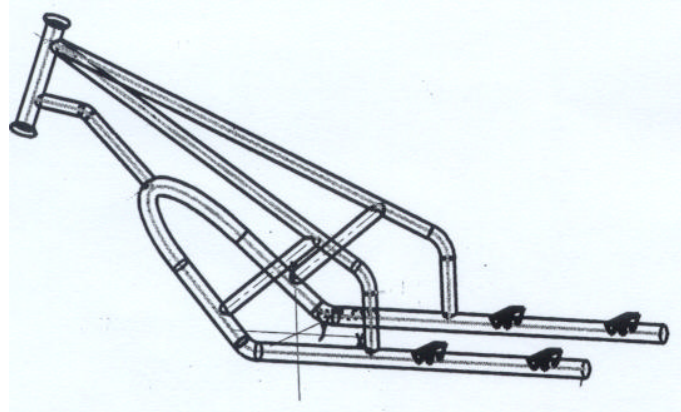

Figure 2 Solid Model of Senior Project No.1 (Chariot Bike Frame) 


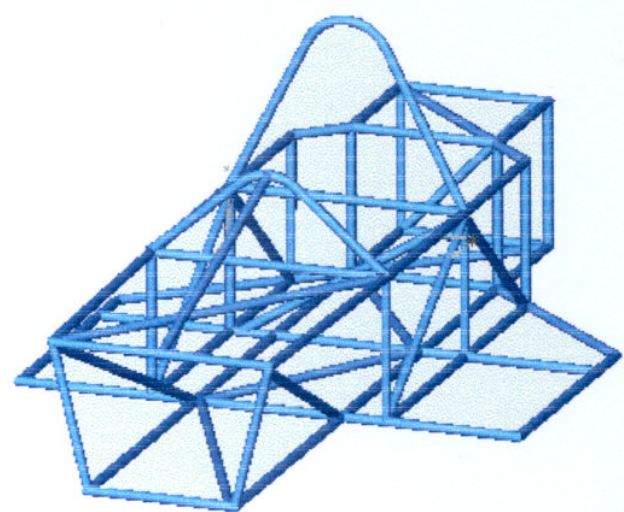

Figure 3 Solid Model of Senior Project No.2 (Racer Car frame)

Before the Mechanical Design Laboratory was available, the majority of senior projects were conducted in any available space that students could find in the Engineering Building. The team might meet at one location for planning and discussion of the project but the actual work on the design was done in another location, and they tended to assign each member a separate piece of the overall design solution. Once the meeting was over, members went separately to perform their own tasks. The tasks could range from generating computer-aided drawings for the design using the CAD lab, searching catalogs of component parts which are located at the student clubroom or machine shop floor, or performing an Internet database search for information located somewhere else in the building. Design analysis and evaluation using the kinematics and the finite element codes were performed in another lab. This distributed arrangement caused team members to work individually for the most part of the project except for some scheduled meetings.

The author's hypothesis is that having essential resources all available in one place for design, the team performance in terms of efficiency and effectiveness would be enhanced. To evaluate this hypothesis, each team was assigned to one table station where computer system for modeling, analysis, and database search was available for various design activities at the beginning of the Fall semester. Team members had almost around the clock access to the Lab, which provided them with the flexibility in scheduling their meetings, in performing group efforts, as well as in doing individual work. Because of the Lab, each team was able to meet on a regular basis since finding a place suitable for design activity is not an issue any more.

Having the computer systems stationed in the Lab made project progress discussions convenient since geometric design models and other relevant data could be retrieved from the computer and discussed in real-time. There were times when an action item or items in the project needed to be addressed immediately, so group members began to work on that task in the same room as soon as the meeting was over either individually or collaboratively. In this way, the project was able to move forward quickly relative to other groups. This advantage was realized in weekly project progress report presented in the class. The available resources and the convenience promoted better teamwork and team performance. Therefore, the duration for completing certain 
tasks for the design was reduced and the project was able to move forward according to the planned schedule.

Members not only benefited from the available resources in the Lab but also were able to constantly be aware of what other members within their team were doing for the project. This implicit learning from others tended to provide broader perspectives on the overall approach of their project and consequently more efficient in solving the design problem. This motivated members to put in their best efforts for reaching the common design goal. To be physically working in the same facility encouraged team collaboration and thus enhanced team communication among members. If a member within the team needed help, the other members were able to provide immediate assistance and could easily make the transition from individual work to a group endeavor. This kind of advantage would not have been realized had the team not worked together in the same place at the same time. Therefore team collaboration was able to minimize project task completion time and potentially maximize the project outcome.

Preliminary Assessment Results

Preliminary assessment of the effects of the Mechanical Design Lab on student projects was based solely on the first semester of these two senior projects. With limited student interview information on hand, the key influences can only be summarized qualitatively as follows:

1. The Lab provided an environment that promoted consistent discipline for students to work on their senior projects.

2. The Lab was the home base where team members gathered for one purpose, that is to work on their senior projects. Because a working station was assigned to each group in the Lab, group members were able to leave their belongings at their station and to meet for discussion at their own schedule without being concerned about space and how to transport project related documents.

3. The Lab's resources (including computer systems, CAD modeling \& finite element analysis capabilities, and internet database connections, etc) provided the team members with the efficiency and the convenience to complete design tasks in a relative short period. The team performance was enhanced and this supports the author's hypothesis.

4. The Lab was relatively quiet compared to other places within the Engineering building, particularly when only one group was present. The atmosphere provided better concentration and fostered more creative thinking for the design.

5. Besides the above positive effects, the Lab also provided the group with an opportunity to establish team spirit early in the project. For the first time in any of their class projects, they felt that team members engaged well in the project in the early stage and were very encouraged by the teamwork.

Conclusion

Based on the feedback from the students in a preliminary assessment, the Mechanical Design Lab contributed to the project's success in many positive ways. The Lab encourages students to be more focus on their project; it provides the environment for teamwork and team communication and collaboration and yet allows individual work to be performed. Because of the Lab's available resources, it also improves the efficiency for students in completing the project tasks. The Lab also serves as home base for fostering creative design work.

Proceedings of the 2002 American Society for Engineering Education Annual Conference \& Exposition Copyright ( 2002, American Society for Engineering Education 
Since only two senior project groups use the Lab at the present time, its ultimate effects on the projects are yet to be assessed. However, as more groups use the Lab for their projects, the demands for more working stations and space, and the scheduling for Lab use might present a challenge. Therefore, lab development fund will be sought to acquire more computer equipment and to provide lab assistants support for maintaining the Lab operation throughout the semester.

\section{Reference}

1. Katzenbach, J.R., and D.K. Smith, The Wisdom of Teams: Creating the High-Performance Organization, Harper Collins, New York, 1999.

2. Michaelsen, L.K., C.F. Jones, and W.E. Watson, "Beyond Groups and Cooperation: Building the HighPerformance Learning Teams," To Improve the Academy: Resources for Faculty, Instructional, and Organizational Development, 1993, Edited by Wright, D.L. and J.P. Lunde, New Forums Press Co., Stillwater OK, 1993.

3. Grulke, E.A., D.C. Beert, and D.R. Lane, "The Effects of Physical Environment on Engineering Team Performance: A Case Study", Journal of Engineering Education, Vol. 90, No. 3, July 2001.

4. Yee, R.K., "Engineering Design Project Experience at SJSU", presented at the San Jose State University Conference, California, titled "Celebrating the Scholarship of College Teaching and Learning” in April 2001.

\section{Biography}

RAYMOND K. YEE, an Associate Professor of the Mechanical and Aerospace Engineering Department at San Jose State University, CA. He received his Ph.D. in ME from the University of California at Berkeley. Professor Yee is a member of ASEE, ASME, and also a Registered Professional Mechanical Engineer in California. His areas of interest in research include finite element method, mechanical engineering design, and fracture mechanics. 